\title{
Lobe of origin in the attribution of lung cancer to asbestos
}

\author{
W WEISS
}

From 3912 Netherfield Road, Philadelphia, PA 19129, USA

\begin{abstract}
Lung cancer originates most commonly in the upper lobes in the general population but among workers with asbestosis it is most common in the lower lobes. Published data on lobar distribution were used to estimate the probabilities that lung cancer among asbestos workers is attributable to exposure to asbestos. This attribution varies directly with the relative risk. Critical values of the relative risk at which attribution of lung cancer to asbestos equalled its attribution to other causes, mainly smoking, were calculated. At a relative risk above $2 \cdot 81$ upper lobe cancers were more likely to be due to asbestos than not. For middle and lower lobe cancers, the critical relative risk was $1 \cdot 55$. These critical values were compared with published standardised mortality ratios reported for cohorts of workers with asbestosis. Since the ratios ranged from $6 \cdot 3$ to $9 \cdot 1$, the probability that lung cancer in such cases is due to asbestos is high regardless of lobe of origin. In many cohorts unstratified by the presence or absence of asbestosis the risk ratios are below one or both of these critical values. Since risk ratios are so high among workers with asbestosis, the ratios must be lower for workers without asbestosis than the overall ratios for unstratified cohorts. Therefore, the critical values may be useful in workers without asbestosis among such cohorts to estimate the upper limit of the probability that lung cancer in a given lobe is due to exposure to asbestos.
\end{abstract}

Some lung cancers are so far advanced when diagnosed that their site of origin cannot be determined. Among those cases in which the lobe of origin may be discerned, however, there is general agreement that lung cancer in the general population is most common in the upper lobes, considerably less common in the lower lobes, and least common in the middle lobe.

Garland $e$ t al reported in 1962 that $67.2 \%$ of 134 cases showed the origin of the tumour to be in the upper lobes, $7.5 \%$ in the middle lobe, and $25.4 \%$ in the lower lobes. ${ }^{1}$ Figures reported by Lulu and Lawson in 1964 for 229 cases were $61 \cdot 1 \%, 9 \cdot 6 \%$, and $29 \cdot 3 \%$ respectively. ${ }^{2}$ In a small series of 41 cases discovered in a semiannual screening programme within six months of a negative film by Weiss and Boucot, the distribution was $65.9 \%, 4.9 \%$, and $29.3 \%$ respectively. ${ }^{3}$ Recently Byers et al presented similar figures in 15477 cases of lung cancer among white men registered by the Surveillance, Epidemiology, and End Results (SEER) Program: $65 \cdot 2 \%, 6 \cdot 3 \%$, and $28 \cdot 5 \%$ respectively. ${ }^{4}$

There has also been consistency in the observation that lung cancer among workers with asbestos exposure originates more commonly in the lower

Accepted 3 August 1987 lobes. ${ }^{5-9}$ Jaoob and Anspach reported in 1965 that the ratio of upper lobe to lower lobe cancers was 1.0:2.2 in Dresden asbestos workers compared with 2.5:1.0 in the general population. ${ }^{5}$ They did not state whether the ratio for asbestos workers was limited to lung cancers in those with asbestosis but the data show that 30 $(86 \%)$ of 35 lung cancers occurred among workers with asbestosis. The other four studies were limited to people with asbestosis. In 1966 Hueper had collected 73 cases of lung cancer in asbestotic subjects with information on lobar site (upper and lower lobes) and recorded data providing a ratio of 1.0:3.9. ${ }^{6}$ Kannerstein and Churg studied 36 cases of lung cancer in asbestos exposed cases, almost all with pulmonary fibrosis, and found the ratio to be 1.0:1.47 compared with 2.42:1.0 among 42 control cases of lung cancer. Whitwell et al reported that $78 \%$ of 65 cases of lung cancer with asbestosis showed origin of the neoplasm in the lower lobes. ${ }^{8}$ Huuskonen studied a cohort of Finnish cases of asbestosis and mentioned that only six of 17 peripheral cancers were in lower lobes, this being the only report at variance with the rest.' In none of these five reports was there information on the degree and duration of exposure to asbestos. It should be noted that among these five papers only the report of Kannerstein and Churg was based on a controlled investigation. 
The purpose of the present paper is to analyse published data so as to provide estimates of the probability that lung cancer is attributable to asbestos in exposed workers when the lobar origin of the cancer is known. Since attributability varies directly with the relative risk, the analysis will be considered in relation to this factor.

\section{Method}

The proportions of lung cancers in upper, middle, and lower lobes in the general male population were derived from the SEER report of Byers et al because of the large number of cases and because the results were population based (table 1). The proportions in asbestotic subjects were taken from the study of Kannerstein and Churg $^{7}$ because, as stated above, this was the only controlled study. Table 1 shows that the proportions among the controls in the study of Kannerstein and Churg were similar to those in the SEER study, an observation that helps to validate the method of Kannerstein and Churg. Despite the small numbers of cases and controls, there was a striking difference in the lobar distributions between the cases and controls. This difference is highly statistically significant (chi square $=9 \cdot 07,0.025>\mathrm{p}>0.01, \mathrm{DF}$ $=2$ ).

The lung cancer proportions by lobe in table 1 were used to generate the relative distributions of nonattributable and attributable cases among asbestos workers at three different values of relative risk. Then comparisons were made with published relative risks.

\section{Results}

Table 2 shows the proportions of non-attributable lung cancers by lobe of origin when the site is known. These are the same as the SEER data in table 1. The asbestos exposed proportions as shown in table 1 were applied to the attributable risks (relative risk minus 1.00 ) in table 2 for comparison. When the relative risk is 2.00 , the attributable risk is 1.00 , so the proportions

Table 1 Proportions of lung cancers by lobe of origin among those with known site in men

\begin{tabular}{|c|c|c|c|}
\hline \multirow[b]{2}{*}{ Lobe } & \multirow[b]{2}{*}{$\begin{array}{l}\text { SEER study } \\
(n=15477)\end{array}$} & \multicolumn{2}{|c|}{ Study of asbestos workers ${ }^{7}$} \\
\hline & & $\begin{array}{l}\text { Controls } \\
(n=42)\end{array}$ & $\begin{array}{l}\text { Exposed } \\
\text { to } \\
\text { asbestos } \\
(n=36)\end{array}$ \\
\hline $\begin{array}{l}\text { Upper } \\
\text { Middle } \\
\text { Lower }\end{array}$ & $\begin{array}{l}0.65 \\
0.06 \\
0.29\end{array}$ & $\begin{array}{l}0.69 \\
0.02 \\
0.29\end{array}$ & $\begin{array}{l}0.36 \\
0.11 \\
0.53\end{array}$ \\
\hline Total & 1.00 & 1.00 & 1.00 \\
\hline
\end{tabular}

Table 2 Relative distribution of lung cancers in asbestos workers by attributability to asbestos, relative risk, and lobe of origin

\begin{tabular}{|c|c|c|c|c|}
\hline \multirow[b]{4}{*}{ Lobe } & \multirow{4}{*}{$\begin{array}{l}\text { Non-attributable } \\
\text { cancers } \\
\text { Relative risk } \\
=1.00\end{array}$} & \multicolumn{3}{|c|}{ Attributable cancers } \\
\hline & & \multicolumn{3}{|l|}{ Relative risk } \\
\hline & & $\begin{array}{l}1.55 \\
\text { Attributable risk }\end{array}$ & 2.00 & $2 \cdot 81$ \\
\hline & & 0.55 & 1.00 & $1 \cdot 81$ \\
\hline $\begin{array}{l}\text { Upper } \\
\text { Middle } \\
\text { Lower }\end{array}$ & $\begin{array}{l}0.65 \\
0.06 \\
0.29\end{array}$ & $\begin{array}{l}0.20 \\
0.06 \\
0.29\end{array}$ & $\begin{array}{l}0.36 \\
0.11 \\
0.53\end{array}$ & $\begin{array}{l}0.65 \\
0.20 \\
0.96\end{array}$ \\
\hline
\end{tabular}

of attributable cases in the various lobes are identical to those given for asbestos exposed cases in table 1 .

The critical value of attributable risk was calculated at which the lower lobe level would equal the level for non-attributable cancers as follows: $0 \cdot 53 \mathrm{X}=0 \cdot 29$, so $X=0.55$. Given the attributable risk of 0.55 , applying 0.11 to 0.55 for the middle lobe level among attributable cancers results in the figure of 0.06 , identical to the level for non-attributable cancers. Applying the upper lobe figure of 0.36 to 0.55 gives a level of 0.20 for upper lobe cancers, which is much lower than the value of 0.65 among non-attributable cancers. Thus at a relative risk of 1.55 , most upper lobe cancers $(0.65 /(0.65+0.20)=0.76$ or $76 \%)$ would be nonattributable. At this relative risk, middle and lower lobe cancers would be equally divided between attributable and non-attributable ones. At lower relative risks, most middle and lower lobe cancers would be non-attributable, and at higher relative risks most middle and lower lobe cancers would be attributable to asbestos.

Similar calculations were made to arrive at the critical value of relative risk for upper lobe cancers in which numbers of attributable and non-attributable cases would be equal. The critical value is a relative risk of 2.81. Above this figure most upper lobe cancers would be attributable to asbestos and below this figure most would be non-attributable.

To assess the relevance of these critical values, they were compared with the relative risks for various published cohort studies. Since the reversal of lobar distribution in asbestos exposed workers has been described essentially only in those with asbestosis, the results in table 2 are relevant only to the relative risks of lung cancer in occupational cohorts of people with asbestosis. To my knowledge, only three studies of this nature provide an estimate of the risk of lung cancer relative to that in the general population and controlled for age, sex, and era- that is, the standardised mortality ratio (SMR).

In 1978 Huuskonen reported a follow up of 174 men 
registered with a diagnosis of asbestosis in Finland between 1964 and 1976. ${ }^{9}$ The criteria for the diagnosis included a history of confirmed occupational exposure to asbestos and a chest $x$ ray film showing small opacities with a profusion of at least $0 / 1$ by the 1972 International Labour Organisation (ILO) classification. Expected numbers of deaths were calculated from 1967 age specific rates for Finnish men. The observed number of deaths from lung cancer was 19 and the expected number was $2 \cdot 1$, giving an SMR of 9.0. All but one of the cases of lung cancer were smokers but SMRs by smoking habits were not provided because the data for non-smokers were too limited. Type of fibre and work exposure were given only for the cases of lung cancer: six of the 19 were anthophyllite miners and the remainder had been exposed to mixed fibres, including nine insulators, four factory workers making asbestos cement products, and one carpenter exposed during construction work.

In 1980 Hobbs et al reported a cohort study of 6200 male western Australian crocidolite miners and millers who worked during the period 1943-66 and were followed up to the end of 1977 . Of these, $220(3.5 \%)$ developed asbestosis but no criteria for the diagnosis were given; 12 died of respiratory cancer when 1.9 were expected based on rates for western Australian men, giving an SMR of 6.3. No information on smoking habits was provided.

In 1981 Berry reported a cohort study of 665 men certified as having asbestosis by three pneumoconiosis medical panels in England and Wales between 1952 and 1976 and followed them up to 1977-8. The diagnosis of asbestosis was based on a history of adequate exposure to asbestos and at least two of the following conditions: basal rales, radiological abnormality, and impaired lung function. One hundred and nine deaths were due to lung cancer with an SMR of 9.1 using rates for England and Wales to calculate the expected number. There was no information on type of work exposure other than the division into laggers and non-laggers and no information on type of asbestos. Smoking habits were known for $96 \%$ of the men but since only $32(4.8 \%)$ had never smoked, this factor was not analysed.

The above SMRs for workers with asbestosis all exceed the critical values calculated in table 2 . Therefore, in the presence of asbestosis, the probability of lung cancer being due to asbestos is high regardless of lobe of origin. The SMR of lung cancer in exposed workers without asbestosis is likely to be $1.00^{12} \mathrm{so}$ in this condition lobe of origin serves no value in estimating the probability that lung cancer is due to asbestos. This issue has been debated, especially in the United States.

Many cohorts of asbestos workers, however, are unstratified by the presence or absence of asbestosis and have SMRs below one or both of the critical values in table 2 . Since the relative risk of lung cancer is
Table 3 Distribution of SMRs for lung cancer in 27 cohorts of asbestos workers*

\begin{tabular}{lc}
\hline$S M R$ & $N o$ \\
\hline$<1.55$ & 10 \\
$1.55-2.81$ & 9 \\
$>2.81$ & 8 \\
\hline
\end{tabular}

*Data from table 5.18 in the report of the Ontario Royal Commission. ${ }^{13}$

high in the presence of asbestosis, it is safe to assume that a cohort with a low relative risk must have many workers without asbestosis that have even lower relative risks than that of the entire cohort. Hence, the relative risk of the entire cohort represents an upper bound for the relative risk of the workers without asbestosis. In this situation lobe of origin may be useful in estimating the probability of attributing the lung cancer to asbestos.

Table 3 provides the distribution of SMRs for lung cancer in 27 cohorts (24 studies) summarised in table 5.18 of the recent review by the Ontario Royal Commission. ${ }^{13}$ Ten of the 27 cohorts had SMRs below the critical value for lower and middle lobe cancers so the probability that cancers of any lobar site are attributable to asbestos in the absence of asbestosis is small. An additional nine cohorts had SMRs above the critical value for middle and lower lobe cancers but below the critical value for upper lobe cancers so the probability that cancers in an upper lobe in such cohorts are attributable to asbestos in the absence of asbestosis is also small.

\section{Discussion}

Since lung cancer is a common disease in the general population and almost entirely due to smoking ${ }^{14}$ the attribution of a particular case to an occupational agent is not easy. Assigning causation of a case to asbestos depends on the presence of asbestosis in countries such as Britain and there is substantial evidence to support this belief. ${ }^{12}$ In the United States this idea remains controversial so any other factors that may help in assigning probability that asbestos is causal can be useful.

As a general principle, in any group of people exposed to a putative agent whose risk of lung cancer is more than double that of an unexposed group the probability that a particular case is due to that agent exceeds the probability that it is not. Any factor that improves predictability on stratification of the group by that factor is of value in enhancing the accuracy of attribution. Thus since the relative risk of lung cancer is higher among asbestos workers with asbestosis than those without it, ${ }^{12}$ the probability that a given case in such workers is due to asbestos is also higher.

The analysis in this report shows that lobar site of origin is another factor that may help in the estimate of attribution, in addition to such variables as degree and duration of exposure, interval from onset of exposure 
and type of work. The striking differences in lobar frequencies of lung cancer in the general population compared with asbestos workers makes this marker of some use when the site of origin can be determined. In most occupational settings the finding of an upper lobe cancer in the absence of asbestosis means that the disease is likely to be due to smoking rather than asbestos since the relative risk must be high to ascribe a cancer in this location to asbestos. The proportions for lobar location in cases with asbestosis used in this analysis, those of Kannerstein and Churg, ${ }^{7}$ were conservative in the sense that they had the highest proportion of upper lobe cancers reported among the four studies which showed a reversal of the lobar pattern of lung cancer in the general population. Consequently, the relative risk required to produce an equal probability that an upper lobe cancer was or was not attributable to asbestos was lower than that required by other published reports ${ }^{568}$ with the single exception of the paper by Huuskonen.'

In some cases even a middle or lower lobe cancer is ascribable to smoking rather than asbestos if the relative risk is low enough. Since almost all lung cancers in populations exposed to asbestos occur in smokers, smoking is not a significant factor in the attribution to asbestos although the interaction between asbestos and smoking is more than additive in the increased risk caused by asbestos. ${ }^{15}$

The importance of relative risk in assessing the probability of attribution is prime. The variability of relative risk in different cohorts, even in the same occupation, underscores the desirability of having cohort specific data with rates stratified by important determinants in making individual estimates of attribution.

The mechanism by which lobar site of origin for a lung cancer is determined remains doubtful. Schlesinger and Lippmann studied particle deposition in the lobar bronchi of hollow casts made of the human tracheobronchial tree ${ }^{16}$ and found that the percentage distribution was similar to that of lung cancers in the general population (see fig 2 in review by Weiss ${ }^{17}$ ). Analogy suggests that tobacco smoke particulates and associated carcinogens may be deposited with the same distribution and account for the lobar origins of lung cancers in the general population.

By contrast, asbestosis tends to be more pronounced in the lower lobes, perhaps reflecting higher concentrations of larger fibres. ${ }^{18}$ How this relates to the higher frequency of lung cancers in the lower lobes is uncertain but there are several possible mechanisms. Asbestos acts like a tumour promoter rather than an initiator in the lung tissue. Most studies show little or no interaction between asbestos and DNA so its role as an initiator is doubtful whereas its activity as a promoting agent is well established. ${ }^{19-21}$ As a promoting agent asbestos fibres seem to act as carriers for adsorbed chemical carcinogens, facilitating transfer of such chemicals into target cells and adduct formation to DNA. ${ }^{21}$ In addition, the greater degree of fibrosis in the lower lobes may enhance cancer formation in these locations by greater interference with the clearance of both fibres and adsorbed chemical carcinogens, resulting in an effectively larger dose in the affected tissues.

\section{References}

1 Garland LH, Beier RL, Coulson W, Heald JH, Stein RL. The apparent sites of origin of carcinomas of the lung. Radiol 1962;78:1-11.

2 Lulu DJ, Lawson LJ. Carcinoma of the lung. Arch Surg 1964;88:213-7.

3 Weiss W, Boucot KR. The Philadelphia pulmonary neoplasm research project: early roentgenographic appearance of bronchogenic carcinoma. Arch Intern Med 1974;134:306-11.

4 Byers TE, Vena JE, Rzepka TF. Predilection of lung cancer for the upper lobes: an epidemiologic inquiry. JNCI 1984;72:1271-5.

5 Jacob G, Anspach M. Pulmonary neoplasia among Dresden asbestos workers. Ann NY Acad Sci 1965;132:536-48.

6 Hueper WC. Occupational and environmental cancers of the respiratory system. New York: Springer-Verlag, 1966:43.

7 Kannerstein M, Churg J. Pathology of carcinoma of the lung associated with asbestos exposure. Cancer 1972;30:14-21.

8 Whitwell F, Newhouse ML, Bennett DR. A study of the histological cell types of lung cancer in workers suffering from asbestosis in the United Kingdom. Br J Ind Med 1974;31: 298-303.

9 Huuskonen MS. Clinical features, mortality and survival of patients with asbestosis. Scand J Work Environ Health 1978;4:265-74.

10 Hobbs MST, Woodward SD, Murphy B, Musk AW, Elder JE. The incidence of pneumoconiosis, mesothelioma and other respiratory cancer in men engaged in mining and milling crocidolite in Western Australia. In: Wagner JC, ed. Biological effects of mineral fibres. Lyon: International Agency for Research on Cancer, 1980:615-25. (IARC publ No 30.)

11 Berry G. Mortality of workers certified by pneumoconiosis medical panels as having asbestosis. Br J Ind Med 1981;38: 130-7.

12 Browne $\mathrm{K}$. Is asbestos or asbestosis the cause of the increased risk of lung cancer in asbestos workers? Br J Ind Med 1986;43: 145-9.

13 Royal Commission on Matters of Health and Safety Arising From the Use of Asbestos in Ontario. Report. Vol 1. Toronto: Ontario Ministry of the Attorney General, 1984:226-30.

14 Surgeon General. The health consequences of smoking: cancer. Rockville, MD: Office on Smoking and Health, 1982:vi. (DHHS (PHS) pub No 82-50179.)

15 Surgeon General. The health consequences of smoking: cancer and chronic lung disease in the workplace. Rockville, MD: Office on Smoking and Health, 1985:217 (DHSS (PHS) pub No 8550207.)

16 Schlesinger RB, Lippmann M. Particle deposition in casts of the human upper tracheobronchial tree. Am Ind Hyg Assoc J 1972;33:237-51.

17 Weiss W. Lung cancer and occupational lung disease. Clin Chest Med 1981;2:289-300.

18 Sebastien P, Fondimare, A, Bignon J, Monchaux G, Desbordes J, Bonnard G. Topographic distribution of asbestos fibres in human lung in relation to occupational and non-occupational exposure. In: Walton WH, ed. Inhaled particles IV. New York: Pergamon Press, 1977:435-46.

19 National Research Council. Asbestiform fibres; nonoccupational health risks. Washington: National Academy Press, 1984: 177-83.

20 Boyland E. Tumour initiators, promoters, and complete carcinogens. Br J Ind Med 1985;42:716-8.

21 Mossman BT, Cameron GS, Yotti LP. Cocarcinogenic and tumor promoting properties of asbestos and other minerals in tracheobronchial epithelium. In: Mass MJ, Kaufman DG, Siegfried HM, Steele VE, Nesnow S, eds. Carcinogenesis. Vol 8. Cancer of the respiratory tract; predisposing factors. New York: Raven Press, 1985:217-38. 